\title{
Rainfall Variation of Peninsular India Reconstructed From a 331- Year-0ld Speleothem
}

\author{
Madhusudan G. Yadava and Rengaswamy R. Ramesh \\ Physical Research Laboratory, Navrangpura, Ahmedabad-380009, India; myadava@prl.ernet.in, r.ramesh@prl.ernet.in
}

The southwest monsoon is of prime importance for the Indian sub-continent as it contributes the majority of annual rainfall. Any major departure from normal monsoon behavior seriously affects agricultural yield and the economy. To enable successful monsoon forecasting in order to plan agricultural activities, a systematic study of variations in monsoonal rainfall is required. This calls for long-term records of past rainfall. In tropical India, the major growth of speleothems occurs during the southwest monsoon (June to September) when water is most abundant. Therefore, speleothems would seem to show good potential as a rainfall proxy.

While $\delta^{18} \mathrm{O}$ of tropical precipitation shows an inverse correlation with the amount of rainfall, it does not show a correlation with surface air temperature (Dansgaard, 1964). Speleothem $\delta^{18} \mathrm{O}$, on the other hand, is related to both the $\delta^{18} \mathrm{O}$ of meteoric water and the temperature of the cave during carbonate precipitation. Therefore, it should in principle function as a proxy for past variations in the $\delta^{18} \mathrm{O}$ of meteoric water and the mean annual surface air temperature. Such an argument can be tested using a young speleothem.

An active stalagmite (Fig. 1), with distinct annual layers covering the past 331 years (the tip is AD 1996), was found in the Akalagavi cave in the mountainous terrain of the Western Ghats, in the state of Karnataka, peninsular India (Yadava et al., submitted). $\delta^{18} \mathrm{O}$ measured along the growth axis varies between -2.7 and $+1.6 \%$ o (Fig. 2). During the past 300 years, mean annual temperature fluctuations of more than $1^{\circ} \mathrm{C}$ (corresponding to only a $\sim 0.22 \%$ o change in the speleothem $\delta^{18} \mathrm{O}$ ) seem unlikely. Hence, past $\delta^{18} \mathrm{O}$ variations in precipitation may have been largely responsible for the variations observed in speleothem $\delta^{18} \mathrm{O}$.

If speleothem $\delta^{18} \mathrm{O}$ is primarily governed by variation in rainfall,

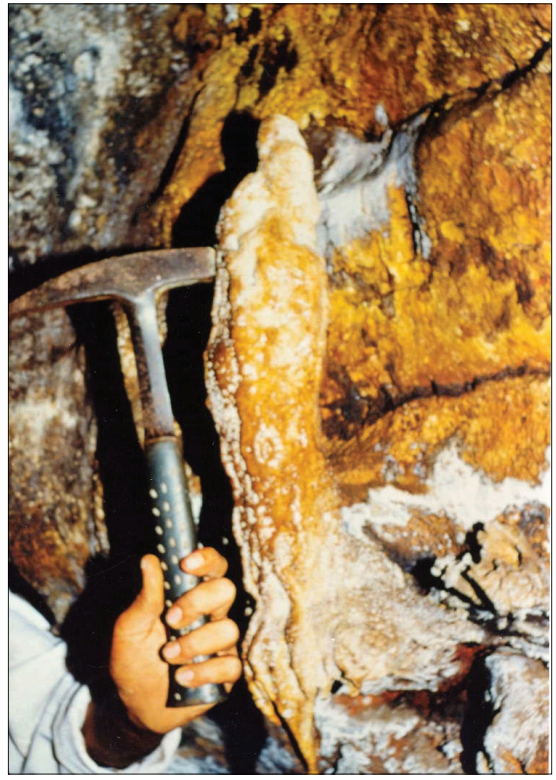

Fig. 1: Akalagavi stalagmite before collection

then a comparison of the $\delta^{18} \mathrm{O}$ time series of the most recent part of the speleothem with the instrumental rainfall record of the region should result in a high correlation coefficient. Indeed, a comparison of the decadal running mean yields a significant value $(r=-0.62, n=80)$. This suggests that $\delta^{18} \mathrm{O}$ in cave deposits is a reasonable proxy for decadal variations in local rainfall. A strong positive correlation $(r=0.62, n=$ 301) between $\delta^{18} \mathrm{O}$ and $\delta^{13} \mathrm{C}$ along the growth axis indicates that on an annual scale, $\delta^{13} \mathrm{C}$ is also correlated with rainfall.

\section{Reconstruction of Rainfall at the Cave Site}

IAEA island stations monitoring $\delta^{18} \mathrm{O}$ in precipitation located in the equatorial belt, where annual temperature fluctuations remain within a narrow range, record a negative correlation between mean monthly $\delta^{18} \mathrm{O}$ of precipitation and mean monthly rainfall (Yurtsever and Gat, 1981). The average rate of depletion is found to be $-1.5 \%$ per $100 \mathrm{~mm}$ increase in monthly rainfall. This depletion rate should also be applicable to the coastal site where Akalagavi cave is located, since annual temperature fluctuations remain within a narrow range. At one of the sites influenced by the southwest monsoon, direct sampling of precipitation samples shows a similar depletion rate (-2.2 $\pm 0.8 \%$ o per $100 \mathrm{~mm}$ ). Fig. 2 shows the $\delta^{18} \mathrm{O}$ of the Akalagavi stalagmite converted into rainfall. Assumptions made include that changes in the speleothem $\delta^{18} \mathrm{O}$ were solely due to variations in the amount-dependent $\delta^{18} \mathrm{O}$ of the annual rain and that the depletion rate observed at the island stations is also applicable to the vapor sources at the cave site.

\section{Period Covered by Instrumental Data (after AD 1813)}

Years in which rainfall at a site is greater than the long-term average rainfall by more than $10 \%$ are defined as "excess" rainfall years (ER). Years in which it is lower by $10 \%$ or more are defined as "deficient" rainfall years (DR). Some of the severely deficient rainfall years $(1982,1979$, 1941, 1925, 1918, 1915, 1905, 1899, $1877,1854,1815)$ as well as most of the excess rainfall years (e.g. 1988, 1975, 1961, 1956, 1953, 1917, 1910, 1894, 1893, 1884, 1878) observed in the AISRTS (All India Summer Rainfall Time Series) are also recorded in our speleothem-based rainfall reconstruction. Differences in timing, ranging from 0-6 years, are most likely due to errors in lamination chronology or to genuine differences in local rainfall as compared with the AISRTS.

The instrumental data in the rainfall reconstruction show an increasing trend over coastal and north-interior Karnataka from 190175. A dry period between 1901-30 in the AISRTS is clearly recorded as shortened width of layers and enriched level of $\delta^{18} \mathrm{O}$ in the speleothem. Similarly, wet conditions from 1931-60 are also reflected in the speleothem. The dry conditions from 1961-90 are marked in our reconstruction by persistent deficient rainfall conditions. However, only some of the individual deficient rain- 


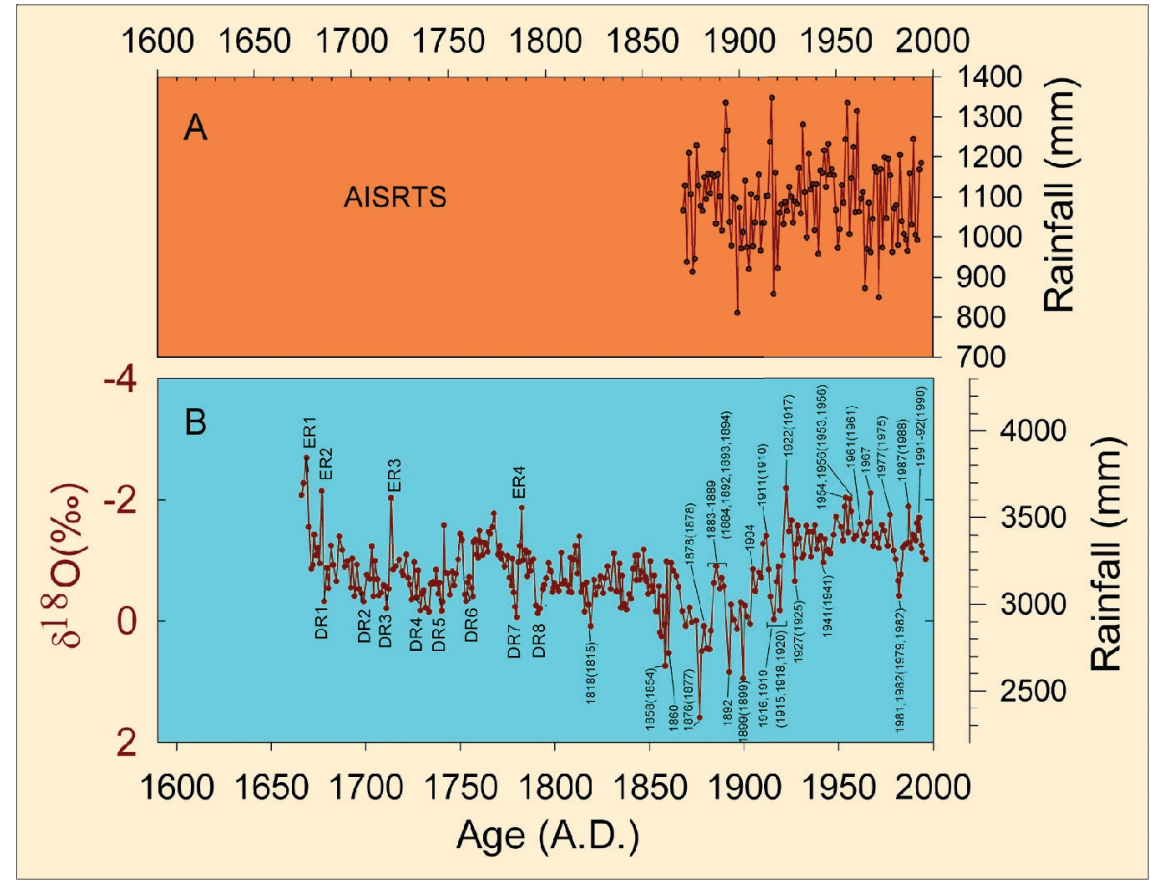

Fig.2: (a) The all India summer rainfall time series (AISRTS) for the period 1871-1994 based on data from 306 stations. (b) $\delta^{18} \mathrm{O}$ versus age obtained from lamination counting. The annual nature of the laminations is supported by the presence of bomb ${ }^{14} \mathrm{C}$ at the tip and agreement between the base ${ }^{14} \mathrm{C}$ age $(210 \pm 100 \mathrm{Yr} \mathrm{BP})$ and the total number of laminations (331). Scale for the rainfall reconstruction is shown on the right. Depleted and enriched $\delta^{18} \mathrm{O}$ signals coincide with excess and deficient rainfall years observed in the AISRTS. The year of their occurrence in the stalagmite is shown by the numbers outside brackets, in the AISRTS by numbers inside brackets. Numbers ER-1 to 4 and DR-1 to 8 are excess and deficient rain years observed before the period covered by instrumental data.

fall years ( 40\%) observed in AISRTS are registered in the stalagmite, while most of the excess rainfall years ( $86 \%)$ are recorded. A possible reason could be the proximity of the cave site to the coast, which would ensure that there were frequent rains due to orographic uplifting of clouds. Hence, a deficiency of rain may not have been experienced at the cave site despite a deficiency
Rainfall Before Instrumental Record (before AD 1813)

Low rainfall events DR7 and DR8 may coincide with the devastating droughts recorded during 1777 and 1796. Other events such as DR1 to DR6 should indicate extremely dry years. Growth in the stalagmite most probably took place when rainfall was high (near ER-1; 1666). A peculiar feature of the rainfall reconstruction is that none of the deficient rainfall conditions observed before 1800 are comparable in magnitude to the deficient years that occurred around 1900. However, the average rainfall before $\sim 1930$ did remain lower than that during 1930 1996. In the reconstruction, all the deficient years (except 1892) and all the excess years (except 1967 and 1905) correlate with similar events in AISRTS. This suggests that there is a high possibility that the extreme events shown by ER1 to ER4 and DR1 to DR8 occurred countrywide.

\section{REFERENCES}

Dansgaard, W., 1964: Stable isotopes in precipitation. Tellus, 16, 436-468.

Yadava, M.G., Ramesh, R. and Pant, G.B.: Past monsoon rainfall variations in peninsular India recorded in a 331 year old speleothem. (Submitted to The Holocenel.

Yurtsever, Y. and Gat, J.R., 1981: Atmospheric waters In Stable Isotope Hydrology: Deuterium and Oxygen-18 in the Water Cycle. Technical Report Series No. 210. (Gat, J.R. and Gonfiantini, Eds.), 103-142, IAEA, Vienna.

\title{
The Potential of Oxygen Isotopes in Diatoms as a Paleoclimate Indicator in Lake Sediments
}

\author{
Angela L. Lamb ${ }^{1}$, Melanie J. Leng ${ }^{2}$, Philip A. Barker ${ }^{3}$ and David W. Morley ${ }^{4}$ \\ ${ }^{1}$ School of Biological \& Earth Sciences, Liverpool John Moores University, UK; a.lamb@livjm.ac.uk \\ ${ }^{2}$ NERC Isotope Geosciences Laboratory, British Geological Survey, UK; mjl@nigl.nerc.ac.uk \\ 3Department of Geography, Lancaster Environment Centre, Lancaster University, UK; p.barker@lancaster.ac.uk \\ 4Environmental Change Research Centre, Department of Geography, University College London, UK; d.morley@ucl.ac.uk
}

Oxygen isotope ratios $\left(\delta^{18} \mathrm{O}\right)$ measured in authigenic minerals are a valuable means of assessing paleoclimate, recording the ambient water temperature and $\delta^{18} \mathrm{O}$ composition of the lake water at the time of formation (see Leng and Marshall, 2004). $\delta^{18} \mathrm{O}$ measured from lake carbonates (authigenic carbonate, ostracods, etc.) has become a well-established paleoclimate technique, but in di- lute and non-alkaline lakes where carbonates are rare, there are only a few suitable alternatives. The measurement of $\delta^{18} \mathrm{O}$ in biogenic silica (mainly diatoms) is being increasingly utilised in low carbonate lakes (e.g. Barker et al., 2001; Shemesh et al., 2001). Diatoms are photosynthetic algae that secrete an internal shell composed of opaline silica $\left(\mathrm{SiO}_{2}-\mathrm{H}_{2} \mathrm{O}\right)$ and are present in most lake sediments apart from some very alkaline lakes (typically $\mathrm{pH}>9$ ), or lakes where silica is limited (Barker et al., 1994). Here we discuss the types of lakes that are most suitable for this technique, the information that can be generated, and the potential problems.

\section{The Effect of Lake Location on $\delta^{18} 0_{\text {diatom }}$ Interpretation}

The majority of lakes, for which oxygen isotope ratios from diatom silica 